\title{
Sobre la responsabilidad y su relación con el daño y los perjuicios ${ }^{1}$
}

About Liability and its Relation to the Damages

\author{
Daniel Ricardo Sarmiento Cristancho ${ }^{2}$ \\ Sindy Viviana Medina Velandía ${ }^{3}$ \\ Rodrigo Alberto Plazas Estepa ${ }^{4}$
}

Fecha de recepción: 30 de noviembre de 2016

Fecha de aprobación: 15 de marzo de 2017

\section{Resumen}

El concepto de responsabilidad civil, desde el punto de vista del daño como fuente, tiene distintas dimensiones jurídicas. Esta relación entre responsabilidad civil y daño se sustenta en sus elementos, los tipos de obligaciones que genera y cómo se caracteriza. Esto teniendo en cuenta que la visión de las altas cortes colombianas se inclina por determinar un vínculo entre las características del daño y la obtención de una indemnización por los perjuicios causados.

Palabras clave: responsabilidad civil, daño, perjuicios, indemnización.

1 Artículo resultado del proyecto de investigación Proceso de Armonización del Derecho Privado en América Latina, del Grupo Derecho Económico y Estado, Corporación Universitaria Republicana. Bogotá, Colombia. DOI: http:// dx.doi.org/10.15332/s1909-0528.2017.0002.04

2 Abogado, consultor en contratación pública y privada y responsabilidad civil. Bogotá, Colombia. Correo electrónico: danielsarmiento@hotmail.com

3 Abogada y especialista en Derecho de Familia de la Corporación Universitaria Republicana. Bogotá, Colombia. Docente investigadora en la línea Derecho Comercial y Financiero del Grupo Derecho Económico \& Estado, Corporación Universitaria Republicana. Bogotá, Colombia. Estudiante de cursos de doctorado de la Universidad de Buenos Aires, Argentina. Correo electrónico: sindy-meve@urepublicana.edu.co.

4 Abogado y Magíster en Derecho Mercantil de la Universidad Sergio Arboleda. Bogotá, Colombia. Docenteinvestigador en la línea Derecho Comercial y Financiero del Grupo Derecho Económico \& Estado; y Director del Centro de Investigaciones de la Corporación Universitaria Republicana. Bogotá, Colombia. Estudiante de cursos de doctorado de la Universidad de Buenos Aires, Argentina. Correo electrónico: rodrigoplazas@ urepublicana.edu.co. 


\begin{abstract}
The concept of civil liabilty from a damage point of view as a source has different legal dimensions. This relationship between civil liability and damage relied upon its elements, the type of obligations generated and how this is characterized. The former takes into account the insights of colombian higher courts, which are prone to determine a linkage between characteristics of the damages and the granting of an indemnity for the prejudices caused.
\end{abstract}

Keywords: Civil liability, Damages, Prejudices, Indemnity. 


\section{INTRODUCTION}

El presente artículo tiene como objetivo determinar la relación entre la responsabilidad y el daño y los perjuicios. En un primer momento, se toman en cuenta las principales nociones relativas a la responsabilidad, para después abordar lo relacionado con la responsabilidad civil extracontractual, tomando como base los pronunciamientos de las altas cortes. Definidos estos términos, se hace un estudio sobre la caracterización del daño, partiendo de los principales elementos tomados en cuenta por la Corte Suprema de Justicia. Dentro de esta caracterización, se asume la imputabilidad y causalidad del daño y las principales características, siendo entre otras que es personal, de carácter cierto y la consolidación de un perjuicio (consolidado y no consolidado). Por último, se analizan los tipos de dańo, destacando el daño emergente y el lucro cesante.

Este artículo utilizó varias herramientas metodológicas para obtener los resultados. La revisión documental e histórica se utilizó para determinar los momentos y las evoluciones de los conceptos de daño y responsabilidad civil. Esto aunado a un análisis jurisprudencial donde no solo el enfoque de ubicar la ratio decindi prima, sino también el obiter dicta puesto que a partir de allí se construyen los conceptos jurídicos objeto de estudio y que solidifican y argumentan la decisión de las sentencias estudiadas. La doctrina, por supuesto, es otra fuente utilizada en la metodología documental, pero con un carácter subsidiario frente a lo evidenciado en lo jurisprudencial.

\section{Principales elementos de la Responsabilidad}

Analizar el origen del marco normativo de la responsabilidad supone contextualizar la iusfilosofía (Durán, 2017). Esto en el sentido del cambio de la naturaleza jurídica de la noción de contrato en razón a que en la actualidad el contrato justo no es solamente aquel regulado por el postulado de justicia y equidad contractual y el respeto a la autonomía de la voluntad como un contrato justo (Gual, 2016), circunstancia que afecta la razón de ser de la responsabilidad jurídica. Es pertinente anotar que para Tamayo (2007) la responsabilidad es la noción en la cual se "engloban 
todos los comportamientos ilícitos que por generar daño a terceros hacen recaer en cabeza de quien lo causó, la obligación de indemnizar. Se puede decir entonces que la responsabilidad civil es la consecuencia jurídica en virtud de la cual, quien se ha comportado de forma ilícita debe indemnizar los daños, producidos a terceros" ( $\mathrm{p}$. 8). Esto significa que la responsabilidad es una obligación que puede tener múltiples fuentes como la ley, el contrato o el daño.

Respecto de la responsabilidad, el Consejo de Estado se ha pronunciado a propósito de la discusión sobre el deber del Estado de responder patrimonialmente por el daño ocasionado, bien por el ejercicio de funciones, como por acción u omisión:

Un sector importante en los dos ámbitos, sostenía que los daños causados con ocasión de la administración de justicia debían ser soportados por los administrados "como una necesidad social" [...] Mientras que otro sector de la doctrina consideraba que la responsabilidad en esta área no solo es posible sino necesaria, ya que los dańos que causen a los particulares tienen una gravedad tanto más condenable cuanto que deben ser soportados en nombre de la justicia (Consejo de Estado, 2006).

\section{RESPONSABILIDAD CIVIL EXTRACONTRACTUAL}

Para la Corte Suprema de Justicia (2000), la responsabilidad civil extracontractual tiene como una de las razones principales que haya una culpa, ya que dicha Corte ha "insistido en que la responsabilidad civil extracontractual prevista en el Código Civil viene impregnada de las tesis subjetivas que entronizan la culpa como criterio fundamental de la responsabilidad".

Asimismo, la Corte Suprema de Justica (2000) plantea que deben estar presentes otros dos factores que se encuentran íntimamente constituidos y que tienen que converger para que pueda existir validez en la respectiva reclamación que se esté desarrollando: por tratarse de una acción de responsabilidad civil extracontractual, su prosperidad demanda la convergencia de los tres elementos que la configuran, a saber: daño, culpa y relación causal entre uno y otra. 


\section{ObligaCiones de MEDio y Obligaciones De RESUlTAdo}

Otro de los elementos que tiene que estar presente es saber comprender las diferencias respecto de las obligaciones de medio. Para Rozo (1999), estas son las que el deudor se responsabiliza de actuar bajo la debida prudencia y diligencia, siempre y cuando se encuentre obligado legalmente. En contraposición, las obligaciones de resultado tienen su base en el contrato, en el cual el deudor debe comprometerse a una acción específica:

La diferencia entre obligaciones de medios y obligaciones de resultado es una diferencia entre dos distintos objetos de la prestación. Precisamente, en las primeras la prestación debida prescinde de un particular resultado positivo de la actividad que le corresponde. Al contrario, en las segundas lo que es debido es el resultado, y para cumplir exactamente la obligación el deudor debe realizar dicho resultado. Si el resultado no se realiza, la obligación se considera incumplida, aunque el deudor se haya comportado diligentemente (Rozo, 1999, p. 139).

\section{Caracterización del daÑo}

La Corte Suprema de Justicia subraya que el daño es ante todo un perjuicio o menoscabo que sufre la víctima, el cual puede ser de carácter patrimonial (afectación) o personal. Esto significa que el daño tiene como una de sus exigencias que se deba y pueda probar por la víctima. Asimismo, esta Corte advierte de la existencia de una nexo causal entre el hecho culposo y el daño causado, luego si no lo hay o se logra probar que no existe tal nexo, el juez está en condiciones de negar las pretensiones solicitadas como consecuencia de una responsabilidad civil, bien sea de carácter contractual o extracontractual.

No obstante, debe destacarse que cuando se está frente a una responsabilidad de medios es dable que pueda determinarse una responsabilidad de resultados, lo que se puede dar v. gr. en los casos de las empresas de seguridad privada, en los cuales una responsabilidad de medios, cuidar un conjunto de apartamentos, se transforma 
en una responsabilidad de resultados cuando dicha empresa no acata los protocolos definidos previamente y en consecuencia, a ese fallo se genera una responsabilidad que no puede catalogarse de medios.

Es importante subrayar que quien cause un daño a otro, de inmediato contrae un deber, en contraposición a la víctima que obtiene un derecho. En el primero, en el causante del daño, surge el deber de indemnizar o reparar a la víctima, luego se hace deudor, en tanto que el otro se hace acreedor, tal como se determina en las obligaciones.

Ahora, esta indemnización, en el marco de las obligaciones, se denomina prestación, de ahí que se diga que la responsabilidad es ante todo una obligación de indemnizar, cuya causa se encuentra en el perjuicio a otra persona. Asimismo, la prestación y la obligación en el marco de la responsabilidad es la indemnización.

Para Escobar (1989, p. 165), el daño "significa todo detrimento, menoscabo o perjuicio que a consecuencia de un acontecimiento determinado experimenta una persona en sus bienes espirituales, corporales o patrimoniales, sin importar que la causa sea un hecho humano, inferido por la propia víctima o por un tercero, o que la causa sea un hecho de la naturaleza".

Otra definición es la dada por Tamayo (2007, p. 326), quien sostiene que "daño civil indemnizable es el menoscabo a las facultades jurídicas que tiene una persona para disfrutar de un bien patrimonial o inmaterial. Ese daño es indemnizable cuando en forma ilícita es causado por alguien diferente de la víctima”.

A este aporte se destaca el dado por De Cupis (1975, p. 81) quien dice que el "daño no significa más que perjuicio, es decir, aminoración o alteración de una situación favorable".

Para Hinestrosa (1967, p. 529), el daño es una "lesión del derecho ajeno consistente en el quebranto económico recibido, en la merma patrimonial sufrida por la víctima, a la vez que en el padecimiento moral que la acongoja”. 
Estas aportaciones dadas por la doctrina se enriquecen con la jurisprudencia, cuando se subraya que el daño es "el detrimento, perjuicio, menoscabo, dolor o molestia causado a alguien, en su persona, bienes, libertad, honor, afectos, creencias, etc., y supone la destrucción o disminución de ventajas o beneficios patrimoniales o extrapatrimoniales de que goza un individuo" (Consejo de Estado, 1999).

Asimismo, la jurisprudencia no ha tenido claridad sobre el daño, pues le ha tratado de forma similar a un perjuicio. No obstante, es importante deslindar ambos conceptos, en la medida que el daño es una lesión en sí misma, es decir, una alteración material externa, en tanto que el perjuicio se puede identificar como las consecuencias del daño, que es en sí una noción de carácter subjetivo que ha sido apreciada o valorada por una persona.

Cabe aclarar que esta distinción ya se venía advirtiendo en la antigua Roma, donde al tratar de sustituir "la noción de damnum por la de perjuicio, comprendieron que lo que importaba no era la comprobación de un atentado material contra una cosa (damnum), sino el perjuicio sufrido a causa de ese hecho por el propietario; por eso decidieron que el simple damnum que no causaba perjuicio no daba lugar a reparación" (Mazeuad, Mazeuad \& Tunc, 1977, p. 40). Profundizando, sobre la relación entre el daño y la responsabilidad, García \& Fernández (1993) subrayan:

El concepto técnico de daño o lesión, a efecto de la responsabilidad civil, requiere, pues, un perjuicio patrimonialmente evaluable, ausencia de causas de justificación (civiles), no en su comisión, sino en su producción respecto del titular del patrimonio contemplado, $y$, finalmente, posibilidad de imputación del mismo a tercera persona. Según se ha visto, la condición necesaria para que desencadene la reparación es que el daño sea antijurídico, calificación que se obtiene de constatar que el ordenamiento jurídico no le ha impuesto a la víctima el deber de soportarlo (García \& Fernández, 1993, p. 63).

Señalan enseguida estos autores que se debe precisar sobre las diferencias entre perjuicio justo e injusto, el cual depende "de la existencia o no de causas de justificación (civil) en la acción personal del sujeto a quien se impute el perjuicio. La causa de justificación ha de ser expresa y concreta y consistirá siempre en un título 
que legitime el perjuicio contemplado: por ejemplo, la exacción de un impuesto, el cumplimiento de un contrato, una ejecución administrativa o procesal. Fuera de esta hipótesis, todo perjuicio o detrimento patrimonial imputable a un sujeto será una lesión, un perjuicio injusto" (García \& Fernández, 1993, p. 63).

Se puede resumir que el daño consiste ante todo en una acción, en un hecho, mientras que el perjuicio es un menoscabo del patrimonio de una persona natural o jurídica, es decir que el patrimonio no sufre un daño como tal, sino un perjuicio.

Con este deslinde conceptual y doctrinario es posible hacer la distinción entre víctima y perjudicado, ya que la primera es la que sufre el daño, bien sea directa o indirectamente, mientras que el segundo es quien sufre las consecuencias, lo que significaría que bien podría ser la víctima o de forma conjunta con otras personas que por diversas razones se establece una relación que también los afecta. Asimismo, se logra comprender que el daño antijurídico corresponde a aquel en el cual la víctima no está en el deber de soportar, lo que podría inferir que hay daño que por el hecho de no ser antijurídico no resulta por ende indemnizable.

\section{IMPUTABILIDAD Y CAUSALIDAD DEL DAŃO}

La imputabilidad hace referencia a un "fenómeno jurídico consistente en la atribución a un sujeto determinado del deber de reparar el daño, con base en la relación existente entre aquel y este" (García \& Fernández, 1993, p. 83).

De igual forma, la causalidad ha sido definida por la doctrina como causalidad material o física, la cual corresponde al fenómeno de efecto físico en el que se plantea que ante un antecedente se genera un resultado. No es lo mismo con la imputación, que es ya la atribución jurídica de un daño, el cual ha sido causado por una persona, de ahí que se dé una imputación. 


\section{Característica del daño}

\subsection{Personal}

El principal criterio es que el demandante logre demostrar que ha sufrido un daño; luego significa que el perjuicio también debe ser personal, lo que le permite acudir a la justicia y obtener la debida indemnización como efecto del perjuicio derivado del daño.

\subsection{Carácter cierto}

Es decir que el mismo se debe probar la existencia del perjuicio (presente o futuro), lo que indica que debe tenerse una valoración de la cuantía del perjuicio patrimonial o de la gravedad de la afectación, en los casos en que dicha afectación sea inmaterial. Frente a la certidumbre del daño, Tamayo (2007, p. 339) dice de forma expresa que "el daño es cierto cuando a los ojos del juez aparece con evidencia que la acción lesiva del agente ha producido o producirá una disminución patrimonial o moral en el demandante".

\subsection{Perjuicio y daño consolidado y no consolidado}

Partiendo de que siempre el perjuicio es futuro en relación con el daño, de ahí que se debe mencionar que el daño es su causal. Asimismo, cuando el daño es anterior a la sentencia judicial es daño anterior o daño consolidado, en tanto que cuando el daño es posterior a la sentencia se habla de daño no consolidado.

\section{Tipos de daÑo}

\subsection{DAÑo EMERGENTE}

El daño emergente es definido por Marińo (1999, p. 6), como "todas las erogaciones o gastos que tuvieron que ser sufragados causa-efecto por un hecho determinado que 
haya causado un daño a la víctima; o sea, las sumas de dinero y los bienes y servicios apreciables en el mismo que tuvieron que salir del patrimonio de alguien por causa del perjuicio causado. También lo son la merma patrimonial que sufre un tercero como consecuencia directa del siniestro".

De acuerdo con este autor, el daño emergente se determina cuando un bien o servicio salió o saldrá del patrimonio de la víctima como consecuencia de los hechos que lo causaron; lo cual significa que no se debe identificar con los perjuicios pasados, por cuanto se limitaría al pasado, es decir, a las erogaciones ya hechas, dejando por fuera el daño emergente futuro que son los gastos futuros que saldrán necesariamente del patrimonio de la víctima, tal como se estimó por parte del Consejo de Estado.

\subsection{Lucro cesante}

Todas las sumas de dinero que para la fecha del hecho generador del daño no habían ingresado al patrimonio de la persona, pero que se esperaba recaudar, ya que las devengaba periódica u ocasionalmente con el empleo o con la actividad económica a la que se dedicaba la víctima, acorde a sus estudios, capacitación, experiencia, etc.; o si, por el contrario, estaba en una improductividad transitoria (infante), vienen los ingresos que hubiera podido percibir una vez alcanzada la mayoría de edad o capacidad productiva (Mariño, 1999, p. 4).

Profundizando, Tamayo (2007) destaca que hay lucro cesante "cuando un bien económico, que debía ingresar en el curso normal de los acontecimientos, no ingresó ni ingresará en el patrimonio de la víctima". La explicación sobre la forma como se puede comprender el lucro cesante es traída a colación por De Cupis, quien lo expresa de la siguiente manera:

El automovilista que atropella a un peatón, perjudica no solo los beneficios del ahorro de los gastos quirúrgicos y hospitalarios (dańo emergente), sino también los que en el futuro hubiese podido adquirir por la permanencia inalterada de su integridad física (lucro cesante). El bien consistente en la suma de dinero que el atropellado se ha tenido que desprender para atender al accidente, le pertenecía ya en el momento del accidente, y, por lo tanto, el 
daño que le corresponde es un daño emergente; mientras que las ganancias profesionales que aquella persona habría obtenido si no se hubiese verificado el accidente son una entidad futura respecto de la que solo puede hablarse de dańo por lucro cesante (De Cupis, 1975, p. 313).

Se entiende entonces cómo el lucro cesante se genera cuando hay una pérdida de perspectiva en cuanto al beneficio. En este sentido, la jurisprudencia señala que dentro de los requisitos que se deben tener en cuenta está: su existencia, sea probado, tenga relación directa con el daño que se haya causado y que se pueda determinar económicamente.

Vale precisar que el artículo 2341 del Código Civil establece la base jurídica de la indemnización: "El que ha cometido un delito o culpa, que ha inferido daño a otro, es obligado a la indemnización, sin perjuicio de la pena principal que la ley imponga por la culpa o el delito cometido". En relación con la indemnización del daño, Henao (2007, p. 313) dice:

En los eventos de indemnización del daño inmaterial la naturaleza de la indemnización, se reitera, es compensatoria, en el sentido de que mediante el bien equivalente del dinero, o, de cualquier otra manera a petición razonable de la víctima o por decisión del juez, se otorga a aquella un bien que le ayuda a aliviar su pena, sin que sea relevante que la indemnización sea o no dineraria [...] Se trata de otorgarle una suma de dinero a una viuda, a un lesionado, para que tenga un bien que le ayude a mitigar su pena.

Se puede concluir que la indemnización de perjuicios extrapatrimoniales se orienta hacia la necesidad de restituir el bien que ha sido lesionado, a fin de que pueda brindarse a la víctima o víctimas la capacidad de compensar o suprimir la pena que se produce como consecuencia del hecho dañoso, lo que permite evitar equiparar los sentimientos con las valoraciones económicas, sino que se establece en sentido contrario. 


\section{Conclusiones}

Podemos concluir que la mejor interpretación que se le puede brindar a un estudioso del derecho de daños o de responsabilidad civil sobre la distinción entre el daño y el perjuicio está en que el daño, en sí mismo considerado, es la lesión al bien jurídico tutelado, mientras que el perjuicio es la afectación de ese bien jurídico tutelado en la realidad, el cual se caracteriza por ser cuantificable ya sea en su valor material o en su valor inmaterial, medido por medio de la intensidad del dańo sufrido.

Un ejemplo de lo anterior, sería la vida. La vida es un bien jurídicamente tutelado, pero si la vida, se pierde (daño) como consecuencia de un accidente de tránsito, entonces hablamos del perjuicio que se causó por la pérdida de esa vida. El daño es la vulneración al bien jurídico tutelado, y el perjuicio será la afectación que causó la perdida de la vida, ya sea a sus herederos o deudores, según el caso.

También podemos concluir que hoy en día para la cuantificación del daño es posible, como lo sostuvo la aclaración de voto a la sentencia proferida por la Sección Tercera del Consejo de Estado, Exp. 17.994, C.P.: Enrique Gil Botero, al sostener que:
2.2. Ahora bien, al examinar el contenido y alcance del artículo 97 del Código Penal vigente (Ley 599 de 2000), se encuentra que, en aquellos eventos en los cuales el daño antijurídico haya tenido origen en una conducta delictiva, independiente al hecho de quien o quienes sean los autores materiales o copartícipes en la comisión del delito, siempre que ese daño resulte imputable al Estado, la valoración del perjuicio extramatrimonial podrá decretarse con base en los baremos de la disposición mencionada.

Sin perjuicio de lo anterior, el mismo Consejo de Estado en documento ordenado mediante acta N.o 23, del 25 de septiembre de 2013, la cual recopila la línea jurisprudencial y establece los criterios unificados para la reparación de los perjuicios inmateriales, documento final aprobado mediante acta del 28 de agosto de 2014, fijó unas tablas o baremos para cuantificar los daños, entiéndase: perjuicios inmateriales, haciendo una relación entre los grados de parentesco de consanguinidad y de afinidad, así como la intensidad del perjuicio que va de un porcentaje superior o igual al $1 \%$, 
hasta un equivalente superior o igual al $50 \%$, para calcular el monto indemnizable, el cual asciende hasta 100 salarios mínimos legales mensuales vigentes.

No debe perderse de vista que la indemnización del daño debe obedecer al principio de valoración de daños, contemplado en el artículo 16 de la Ley 446 de 1998, el cual menciona que: "Dentro de cualquier proceso que surta ante la administración de justicia, la valoración de daños irrogados a las personas y a las cosas, atenderá los principios de reparación integral y equidad y observará los criterios técnicos actuariales".

Como tampoco el hecho que se puede hacer gala del bloque de constitucionalidad, en virtud del cual se puede aplicar por ejemplo un fallo proferido por la Corte Interamericana de Derechos Humanos, en un caso análogo dentro del territorio, para pretender una indemnización por concepto de indemnización de perjuicios.

Así las cosas, el jurista que pretenda la indemnización del daño, cuenta con varios caminos que le permitirán lograr su cometido en las pretensiones que formule.

Por otro lado, y en relación con la responsabilidad civil extracontractual, debemos mencionar que el elemento subjetivo, es decir, la culpa, se está quedando rezagada en atención al mismo daño. Poco importa si se actuó con culpa o sin ella, lo que importa es que se indemnice el perjuicio causado, a menos que exista una causa extrańa, como eximente de responsabilidad y, en consecuencia, de resarcir por el daño causado.

Diferente circunstancia, si hablamos de la responsabilidad civil contractual, la cual por expresa disposición legal, contenida en el artículo 1604 del Código Civil, se presume la culpa del deudor, y será este quien deba demostrar que actuó con diligencia y cuidado para lograr un eximente de responsabilidad, ya que de lo contario, será obligado a pagar las indemnizaciones a que hubiere lugar, según el tipo de obligación incumplida.

Finalmente, es importante recordar siempre —como lo mencionaba reiteradamente Hernán Fabio López Blanco en sus intervenciones académicas: "El que alega, prueba; y el que prueba, gana” — demostrar los elementos que estructuran la responsabilidad 
civil: el factor de atribución, el nexo causal y el daño es tan importante como demostrar que el daño es cierto, personal y directo.

El éxito de las pretensiones en un proceso de responsabilidad civil, en el cual se solicita el reconocimiento de daños y la indemnización de perjuicios, se encuentra en las pruebas que se aporten al proceso, y la acuciosa fundamentación de hermenéutica jurídica que permita traer a colación las últimas tendencias en derecho de daños.

\section{REFERENCIAS}

De Cupis, Adriano (1975). El Daño. 2. edición. Barcelona: Editorial Bosch.

Durán, J. (2017). Tercera vía en filosofia del Derecho. Bogotá: Editorial Ibáńez.

Escobar, Rodrigo (1989). Responsabilidad contractual de la administración pública. Bogotá: Editorial. Temis.

García de Enterría, Eduardo \& Fernández, Tomás (1993). Curso de Derecho Administrativo. Madrid: Editorial Civitas.

Gual, José Manuel (2016). “Las cláusulas abusivas. Evolución hacia una noción”. En Revista Verba Iuris. 11(36), pp. 113-134.

Henao, Juan Carlos (2007). El daño. Análisis comparativo de la responsabilidad extracontractual del estado en Derecho colombiano y francés. Bogotá: Universidad Externado de Colombia.

Hinestrosa, Fernando (1967). Derecho de Obligaciones. Bogotá: Universidad Externado de Colombia.

Mariño, Luis Eduardo (1999). Manual práctico de indemnización de perjuicios. Bogotá: Editorial Librería del Profesional. 
Mazeuad, Henri; Mazeaud, León \& Tunc, André (1977). Tratado teórico y práctico de la responsabilidad civil delictual y contractual. Traducido por Luis Alcalá Zamora, T I. 5.o ed. Buenos Aires: Editorial. Jurídicas Europa-América, 1977.

República de Colombia. Consejo Nacional Legislativo (1887). Ley 57 (15 de abril de 1887). Código Civil. Bogotá: autor.

República de Colombia. Consejo de Estado. Sección Tercera (1999). Procesos Acumulados 10948-11643. Consejero Ponente Alier Eduardo Hernández Enríquez.

República de Colombia. Consejo de Estado (2000). Sentencia 11.842, 19 de julio de 2000. C.P. Alier Eduardo Hernández Enríquez.

República de Colombia. Consejo de Estado. Sección Tercera (2006). Sentencia 14.837, 27 de abril de 2006. C. P. Alier Eduardo Hernández Enríquez.

Tamayo, Javier (2007). Tratado de Responsabilidad Civil. T I. Bogotá: Editorial Legis S.A.

Tamayo, Javier. (2007). Tratado de Responsabilidad Civil. T II. Bogotá: Editorial Legis S.A. 